\title{
Opportunities and challenges in monsoon prediction in a changing climate
}

\author{
B. N. Goswami • R. Krishnan
}

Published online: 13 June 2013

(C) Springer-Verlag Berlin Heidelberg 2013

The South Asian monsoon is the pulse and life-line of over two billion inhabitants of the Indian subcontinent. The socio-economic development in this part of the world heavily depends on reliable predictions of the seasonal monsoon rainfall. Notwithstanding notable progress made in seasonal prediction of tropical climate during the past few decades, reliable forecasting of the South Asian summer monsoon has remained a 'grand challenge' problem. The problem gets more complicated in a warming environment with possible further degradation of the potential predictability. To define a way forward, an international Conference on "Opportunities and Challenges in Monsoon Prediction in a Changing Climate" (OCHAMP-2012) was organized during the period 21-25 February, 2012 at Pune, India, by the Indian Institute of Tropical Meteorology in association with World Climate Research Programme and World Weather Research Programme of World Meteorological Organization (WMO). The Conference was organized also to commemorate the Golden Jubilee of the Indian Institute of Tropical Meteorology.

In order to make tangible progress on the challenging problem of monsoon prediction, it was recognized that it would be crucial to expand the base of monsoon research. Therefore, in addition to a large number of eminent monsoon experts, more than 150 early career scientists and young scholars were supported to participate in OCHAMP2012, which was attended by more than 350 participants.
The scientific presentations during OCHAMP covered overview talks and original contributions, on different facets of monsoon research (viz., prediction and predictability of the monsoon, monsoon variability through observations and processes, status of modeling the monsoon and its variability, Monsoon weather predictability in a changing climate scenario, Interactions of tropical clouds and aerosol on Asian monsoon, Emerging role of Indian ocean on monsoon dynamics, Paleo-climatic studies in relation to monsoon variability). Several important scientific issues were deliberated during the panel discussions including, approaches to address biases in current climate models, advancing the skill of dynamical prediction of monsoon weather and climate and quantification of role of aerosols in modulating the monsoon rainfall, etc.

The diversity of presentations during the OCHAMP conference is clearly reflected from the 12 papers, on different themes dealing with the science of monsoons, which are being published in this special issue of Climate Dynamics. These papers were shortlisted based on their merit and relevance to the conference. We wish to acknowledge the support of the Ministry of Earth Sciences, Government of India, the World Climate Research Program and the World Weather Research Program of WMO. This special issue of OCHAMP was coordinated by Dr. R. Krishnan and Dr. G. Pandithurai.

Guest Editors 